\title{
The RNAi vecter construction and verification of the functions in sexual control of Cervus elaphus Zfx gene
}

\section{Limin Wei}

Sichuan Agricultural University

\section{Song Jiang}

Shihezi University

Jifeng Xi

Shihezi University

Yongsheng Zhang

Shihezi University

\section{Bo Zeng}

Sichuan Agricultural Univeristy

\section{Feng Li}

Sichuan Agricultural University

\section{Kaisheng Wang}

Yulin Normal University

\section{Siyuan Zhang}

Sichuan Agricultural university

\section{Hong Shen}

Shihezi University

Bin Jia ( $\square$ jiabinxj@163.com )

Shihezi University

\section{Research article}

Keywords: Zfx , RNAi, Cervus elaphus, Sex control

Posted Date: January 15th, 2020

DOI: https://doi.org/10.21203/rs.2.19002/v2

License: (c) (i) This work is licensed under a Creative Commons Attribution 4.0 International License.

Read Full License 
The authors have withdrawn this preprint from Research Square 